\title{
Altered methionine metabolism in streptozotocin-diabetic rats
}

\author{
N.T.Glanville and G.H.Anderson \\ Department of Nutritional Sciences, University of Toronto, Toronto, Canada
}

\begin{abstract}
Summary. We examined the origin of hypermethioninaemia in streptozotocin-diabetic rats. In rats administered streptozotocin over a range from 55 to $75 \mathrm{mg} / \mathrm{kg}$, the dose of drug injected correlated directly with the plasma methionine concentration and inversely with the plasma insulin level. Although insulin administration prevented hypermethioninaemia in streptozotocin-diabetic rats, discontinuing insulin treatment resulted in a time-dependent increase in the plasma methionine level. Plasma methionine concentration was, however, normal in insulin-deprived BB Wistar rats despite severe hyperglycaemia. Thus, although insulin deficiency may be a contributing factor, it does not cause hypermethioninaemia
\end{abstract}

independent of other drug-related effects. Administering a loading dose of methionine $(100 \mathrm{mg} / \mathrm{kg})$ indicated that streptozotocin-diabetic rats have a reduced metabolic capacity. Since dietary intake is the primary source of methionine, it is likely that hyperphagia combined with limited disposal produces hypermethioninaemia. Methionine is the most toxic amino-acid; therefore, metabolic studies using the streptozotocin model of insulin deficiency must be interpreted with caution.

Key words: Streptozotocin diabetes, insulin deficiency, methionine, hypermethioninaemia, drug toxicity.
Streptozotocin (STZ) is a $\beta$ cell-cytotoxic agent commonly used to induce experimental diabetes in rodents [1]. Using this model, the effect of insulin deficiency on the metabolism of branched chain and gluconeogenic amino-acids has been extensively studied $[2,3]$. Other amino-acids have received less attention. We observed a sevenfold increase in the plasma methionine concentration of STZ-diabetic rats [4], although a marked increase in the plasma level of this amino-acid is not usually associated with insulin deficiency $[2,3]$. The object of this study, therefore, was to determine the origin of hypermethioninaemia in STZ-diabetic rats.

\section{Materials and methods}

\section{Experimental design}

Five experiments were conducted. (1) The relationship between the dose of STZ administered and plasma methionine concentration was established by injecting animals with 55,65 or $75 \mathrm{mg} / \mathrm{kg}$ of STZ. (2) The effect of insulin administration on plasma methionine concentration in STZ-diabetic rats $(75 \mathrm{mg} / \mathrm{kg})$ was determined by treating rats with $1 \mathrm{U} /$ day of protamine zine insulin (Connaught Laboratories, Willowdale, Ontario) and withdrawing therapy for $12 \mathrm{~h}, 36 \mathrm{~h}, 60 \mathrm{~h}$, 5 days or 8 days before sacrifice. (3) The effect of insulin deficiency on plasma methionine concentration was examined independent of STZ exposure by depriving spontaneously diabetic BB Wistar rats $(278 \pm$ $14 \mathrm{~g}$; pre-diabetic control rats $312 \pm 11 \mathrm{~g}$ ) (Banting and Best Research Institute, Toronto, Ontario) of maintenance injections of insulin ( $2.5 \mathrm{U} /$ day) for $36 \mathrm{~h}$ or $60 \mathrm{~h}$ before sacrifice; and by administering a sub-maintenance dose of insulin $(0.5 \mathrm{U} /$ day $)$ for 5 days before sacrifice. (4) The ability of rats to clear a methionine load was assessed by administering methionine $(100 \mathrm{mg} / \mathrm{kg}$, intraperitoneally) (Grand Island Biological Company, Grand Island, New York) to (a) food-deprived normal and STZ-diabetic rats $(75 \mathrm{mg} / \mathrm{kg}$ ) and (b) food-deprived pre-diabetic $(347 \pm 5 \mathrm{~g})$ and diabetic $(296 \pm 10 \mathrm{~g}) \mathrm{BB}$ Wistar rats treated with $0.5 \mathrm{U} /$ day of insulin. In part (a), rats were sacrificed between 16.00 and $19.30 \mathrm{~h}$ at $0,30,90$ and $210 \mathrm{~min}$ intervals. In part (b), tail vein blood samples were obtained at 0 and $90 \mathrm{~min}$. (5) The effect of STZ administration $(100 \mathrm{mg} / \mathrm{kg})$ on food intake in large rats $(300 \mathrm{~g})$ was evaluated. Rats were initially treated with insulin (2.5 U/day). Following withdrawal of insulin therapy, food intake was monitored at 24-h intervals.

All STZ-diabetic rats were killed on day 10 post-induction. All animals were fed a semi-purified diet containing $20 \%$ protein (casein) formulated as described previously [5]. Food intake and weight gain were measured every 3 days.

\section{Production of diabetes}

Male Wistar rats (Woodlyn Farms, Guelph, Ontario) with an initial weight of $80-100 \mathrm{~g}$ (experiments $1,2,4$ ) or $300 \mathrm{~g}$ (experiment 5) were housed individually in wire meshed hanging, stainless steel cages in a room kept at $23^{\circ} \mathrm{C}$ and lit for $12 \mathrm{~h}$ daily $(08.00-20.00 \mathrm{~h}$ ). Streptozotocin (Sigma Chemicals, St. Louis, Missouri, USA) was individually weighed for each rat, dissolved in $0.25 \mathrm{ml}$ of $150 \mathrm{mmol} / 1$ saline, ad- 
Table 1. Relationship of streptozotocin dose to weight gain, plasma glucose, insulin, methionine, half-cystine and hepatic cystathionase activity in diabetic rats

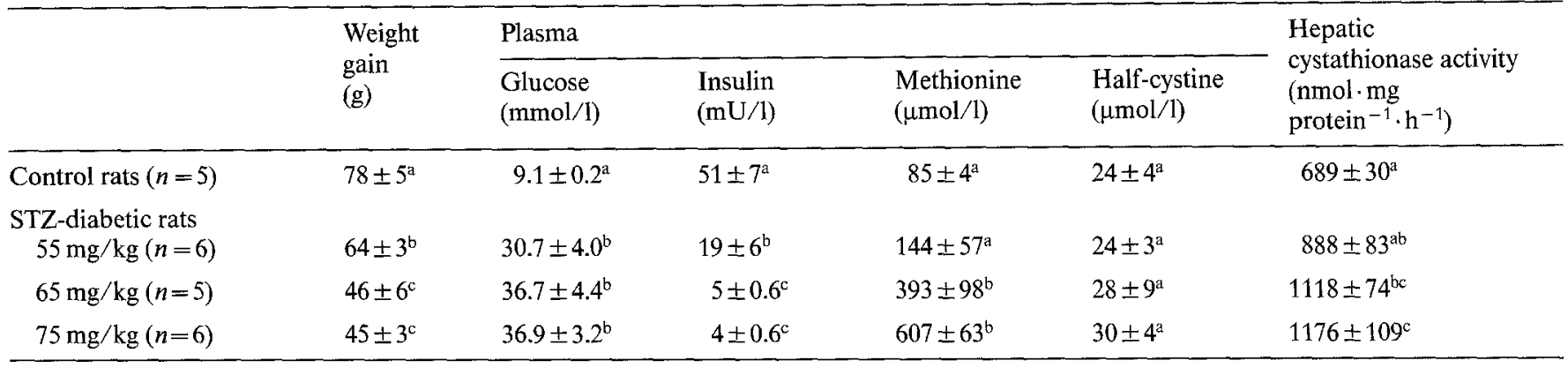

Results are expressed as mean \pm SEM. ${ }^{a}, b, c$ superscript notation for Tukey's multiple range $t$-test. Values sharing a common superscript are not significantly different $(p>0.05)$.

justed to $\mathrm{pH} 4.4$ with citric acid $(0.05 \mathrm{~mol} / \mathrm{l})$ and immediately administered intraperitoneally. Control animals received vehicle only. All injections were given between 16.30 and $17.30 \mathrm{~h}$ following a $16-\mathrm{h}$ fast. The presence of diabetes was verified by estimates of urinary glucose (Clinitest Reagent, Ames Divison, Miles Laboratories, Rexdale, Ontario) and blood glucose (GOD-PAP, Boehringer Mannheim, Mannheim, FRG). Animals with urinary glucose excretion $<100 \mathrm{mmol} / 1$ and blood glucose levels $<16 \mathrm{mmol} / 1$ were discarded. Diabetic animals exhibited polydipsia, polyuria and hyperphagia. Ketonuria (Acetest Reagent, Ames Division, Miles Laboratories) was not generally observed.

\section{Tissue analysis}

All animals were allowed access to food overnight and killed by decapitation between 09.00 and $11.00 \mathrm{~h}$ unless indicated otherwise. Blood from the cervical stump was collected into chilled, heparinized tubes and centrifuged at $1000 \mathrm{~g}$ for $10 \mathrm{~min}$. Plasma was deproteinized immediately with an equal volume of $15 \%$ sulphosalicyclic acid containing norleucine as internal standard and stored at $-70^{\circ} \mathrm{C}$ until analyzed for amino-acids using an amino-acid analyzer (model 116/119, Beckman, Palo Alto, California). In experiment $4 \mathrm{~b}$, plasma methionine was determined by high performance liquid chromatography (Waters Associates, Milford, Massachusetts) using pre-column derivatization with fluoroesence detection [6]. Insulin was determined using a single antibody with dextran coated charcoal separation [7] and calibrated using a rat insulin standard. Hepatic cystathionase activity was assessed by the method of Gaull et al. [8] and Gaitonde [9] using L-cystathionine (Cal Biochem-Boering, San Diego, California) as substrate. Protein was determined according to the method of Lowry et al. [10].

\section{Statistical methods}

All values are expressed as mean \pm SEM. Tukey's multiple range T-test, two way analysis of variance, correlational analysis and linear regression were used to analyze the data where appropriate [11]. Significance was established at the 0.05 level of probability.

\section{Results and Discussion}

Hypermethioninaemia in STZ-treated Wistar rats was related to the dose of drug administered. When animals were injected with STZ over a range from 55 to $75 \mathrm{mg} /$ $\mathrm{kg}$, rats administered either 65 or $75 \mathrm{mg} / \mathrm{kg}$ exhibitea five- to sixfold increase in plasma methionine concentration, while that of the $55 \mathrm{mg} / \mathrm{kg}$ group was not differ-
Table 2. Plasma methionine and glucose in STZ-diabetic and BB Wistar rats deprived of insulin

\begin{tabular}{lcc}
\hline & $\begin{array}{c}\text { Methionine } \\
(\mu \mathrm{mol} / 1)\end{array}$ & $\begin{array}{c}\text { Glucose } \\
(\mathrm{mmol} / \mathrm{l})\end{array}$ \\
\hline $\begin{array}{l}\text { Control rats }(n=9) \\
\text { STZ-diabetic rats }\end{array}$ & $57 \pm 9^{\mathrm{a}}$ & $8.9 \pm 0.2^{\mathrm{a}}$ \\
$\quad$ 12h post-insulin $(n=7)$ & $48 \pm 10^{\mathrm{a}}$ & $19.7 \pm 3.2^{\mathrm{b}}$ \\
36h post-insulin $(n=9)$ & $78 \pm 11^{\mathrm{a}}$ & $20.5 \pm 3.8^{\mathrm{b}}$ \\
60h post-insulin $(n=9)$ & $162 \pm 39^{\mathrm{ab}}$ & $31.2 \pm 0.9^{\mathrm{c}}$ \\
5 days post-insulin $(n=8)$ & $447 \pm 114^{\mathrm{b}}$ & $30.6 \pm 1.7^{\mathrm{c}}$ \\
8 days post-insulin $(n=8)$ & $312 \pm 104^{\mathrm{ab}}$ & $33.9 \pm 1.6^{\mathrm{c}}$ \\
$\quad$ no insulin $(n=8)$ & $441 \pm 123^{\mathrm{b}}$ & $39.1 \pm 0.9^{\mathrm{c}}$ \\
Non-diabetic BB Wistar rats $(n=6)$ & $30 \pm 5^{1}$ & $11.0 \pm 1.8^{1}$ \\
Diabetic BB Wistar rats & & \\
$\quad$ 36h post-insulin $(n=6)$ & $35 \pm 6^{1}$ & $31.1 \pm 2.1^{2}$ \\
60 h post-insulin $(n=5)$ & $37 \pm 6^{1}$ & $28.9 \pm 2.5^{2}$ \\
\hline
\end{tabular}

a Animals were treated with insulin ( $1 \mathrm{U} /$ day).

b Animals were treated with insulin ( $2.5 \mathrm{U} /$ day).

Results are expressed as mean \pm SEM. ${ }^{a, b, c, 1,2}$ Superscript notation for Tukey's multiple range t-test. Within each treatment group, values sharing a common superscript are not significantly different $(p>0.05)$

ent from normal (Table 1). In these rats, the dose of STZ injected correlated directly with the plasma methionine concentration $(r=0.65, \mathrm{df}=20, p \leq 0.01)$ and inversely with the plasma insulin level $(r=-0.88, \mathrm{df}=20, p \leq$ 0.01).

Manipulating the dose of STZ administered altered both the degree of insulin deficiency and the potential for the toxin to have other effects. To isolate the origin of elevated plasma methionine in STZ-diabetic rats, we first examined the effect of insulin replacement. Although insulin administration prevented hypermethioninaemia, plasma methionine concentration increased after insulin withdrawal (Table 2). However, when spontaneously diabetic BB Wistar rats, a model where insulin deficiency can be examined independent of STZ exposure, were completely deprived of insulin for $60 \mathrm{~h}$, plasma methionine levels remained normal (Table 2). Moreover, in contrast to the eightfold increase observed in STZ-diabetic rats, plasma methionine levels in BB Wistar rats, treated chronically with $0.5 \mathrm{U} /$ day of insu- 


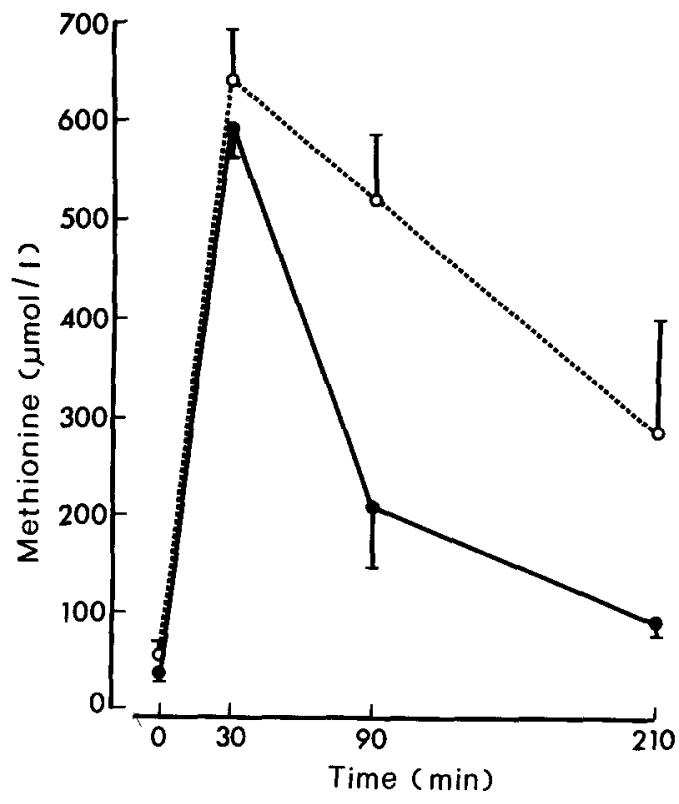

Fig. 1. Methionine clearance in STZ-diabetic (O-.---.-O) and normal rats (-) administered methionine at a dose of $100 \mathrm{mg} / \mathrm{kg}$. Results are expressed as mean $\pm \operatorname{SEM}(n=6)$. Statistical comparison was by two way analysis of variance: treatment effect $(1,10) \mathrm{F}=14.09$, $p<0.01 ;$ time effect $(3,30) \mathrm{F}=33.64, p<0.01$

lin and similarly hyperphagic to the STZ-diabetic rats, were elevated by only $20 \%$ above levels in food-deprived control rats. These observations suggest that although insulin deficiency contributed to hypermethioninaemia in STZ-diabetic rats, it did not cause altered methionine metabolism independent of other unknown effects of the drug.

To examine further the origin of hypermethioninaemia, STZ-diabetic rats were administered a dose of methionine $(100 \mathrm{mg} / \mathrm{kg})$ equivalent to that contained in a $3 \mathrm{~g}$ meal of a $20 \%$ casein diet. Although the basal level and the increase at $30 \mathrm{~min}$ were similar to that of normal animals, plasma methionine levels in STZ-diabetic rats remained elevated at 90 and $210 \mathrm{~min}$ (Fig. 1). Because the basal insulin level in normal rats $(25 \pm 2 \mathrm{mU} / \mathrm{l})$ was threefold higher than in STZ-diabetic rats $(7 \pm 1 \mathrm{mU} / 1)$, it is possible that the difference in methionine clearance rate was due to increased incorporation into protein by normal rats rather than reduced catabolism by STZ-diabetic rats. To answer this question, we conducted a similar experiment using diabetic BB Wistar rats with symptoms of insulin deficiency similar to that exhibited by STZ-diabetic rats. That is, they were non-ketotic but had significant hyperphagia $(25 \pm 2 \mathrm{~g} /$ day; pre-diabetic control rats $17 \pm 0.5 \mathrm{~g} /$ day) and glycosuria $(9 \pm 2 \mathrm{~g} /$ $24 \mathrm{~h}$ ). At $90 \mathrm{~min}$, the point of maximum difference between normal and STZ-diabetic rats, the plasma methionine levels in diabetic BB Wistar rats $(431 \pm 14 \mu \mathrm{mol} /$ $1, n=6)$ and pre-diabetic control rats $(431 \pm 12 \mu \mathrm{mol} / 1$, $n=6)$ were identical. These results indicate that factors other than insulin deficiency contributed to the limited capacity of STZ-diabetic rats to metabolize methionine.
A limited capacity to catabolize methionine might be predicted from the hepatocellular damage caused by STZ $[12,13]$, since methionine is metabolized primarily in liver tissue. To assess the capacity for methionine catabolism, we measured hepatic cystathionase activity as an index of transulphuration. In STZ-diabetic rats, cystathionase activity was increased over the control value while plasma half-cystine levels remained unchanged (Table 1). Probably because of increased age [14], cystathionase activity was $40 \%$ higher in the BB Wistar rats compared with the STZ-diabetic rats. However, the level in BB Wistar diabetic rats $(1841 \pm 146 \mathrm{nmol} \cdot \mathrm{mg}$ protein $\left.^{-1} \cdot \mathrm{h}^{-1}\right)$ was similar to that of prediabetic control rats $\left(1685 \pm 67 \mathrm{nmol} \cdot \mathrm{mg}\right.$ protein $\left.{ }^{-1} \cdot \mathrm{h}^{-1}\right)$. It is possible, therefore, that the increased transulphuration activity observed in STZ-diabetic rats arises from decreased transamination activity, the other major catabolic pathway [15]. However, the metabolic origin of the reduced capacity to catabolize methionine remains undetermined.

Because methionine cannot be synthesized de novo within the body, our results indicate that hypermethioninaemia in STZ-diabetic rats results from the combined effects of persistent hyperphagia throughout both the light and dark periods [16] and reduced capacity to metabolize methionine. The observed hyperphagia and hypermethioninaemia coinciding with insulin withdrawal are consistent with this interpretation. Moreover, in contrast to the fed state, plasma methionine concentration in food-deprived STZ-diabetic rats was normal despite equivalent low ambient insulin levels. Thus, normalization of plasma methionine in insulintreated and food-deprived STZ-diabetic rats may be attributed to decreased intake rather than a reversal of tissue damage.

Although we have consistently observed hypermethioninaemia in young $(120 \mathrm{~g})$ Wistar rats, our results appear to be in contrast with the normal plasma methionine levels reported in older ( $300 \mathrm{~g})$ Sprague-Dawley rats administered $100 \mathrm{mg} / \mathrm{kg} \mathrm{STZ}$ and sacrificed $90 \mathrm{~h}$ post-insulin withdrawal [3]. Therefore, we administered $100 \mathrm{mg} / \mathrm{kg} \mathrm{STZ}$ to $300 \mathrm{~g}$ Wistar rats and monitored food intake during the period of insulin withdrawal. In this experiment, food intake was decreased by $50 \%$ at $84 \mathrm{~h}$ post-insulin with five of the seven rats studied dying within the next $24 \mathrm{~h}$. This suggests that the severe metabolic decompensation induced by this dose of STZ precluded the development of hyperphagia and hypermethioninaemia. Whether altered methionine metabolism would be manifested in old rats administered a smaller dose of STZ remains to be determined. Food intake per unit of body weight is greater in young rats, however, suggesting that hypermethioninaemia may be confined to STZ-induced diabetes in young, developing, hyperphagic animals.

In conclusion, the metabolism of methionine in STZ-diabetic rats is related not only to insulin deficiency but also to other unknown effects of drug exposure. 
Methionine is the most toxic amino-acid. When hypermethioninaemia is induced by feeding diets containing excess quantities of this amino-acid, animals exhibit growth failure [17, 18], renal tubular hypertrophy [19], pancreatic acinar cell damage $[19,20]$, atrophy of liver cells [21], and anaemia with iron accumulation in the liver and spleen [19, 21]. Thus, the results of metabolic studies employing the STZ model of insulin deficiency must be interpreted with caution.

Acknowledgements. The authors wish to thank Dr. J. Logothelopoulos for generously providing the BB Wistar rats and Dr. J. Martin for his assistance in performing the insulin assay. This work was supported by the Natural Sciences and Engineering Research Council of Canada. N. T. Glanville is the recipient of a Medical Research Council of Canada Studentship award.

\section{References}

1. Rerup CC (1970) Drugs producing diabetes through damage of the insulin secreting cells. Pharmacol Rev 22: 485-518

2. Bloxam DL (1972) Nutritional aspects of amino acid metabolism: 3 . The effect of diabetes on blood and liver amino acid concentrations in the rat. Br J Nutr 27: 249-259

3. Brosnan JT, Man KC, Hall DE, Colbourne SA, Brosnan ME (1983) Interorgan metabolism of amino acids in streptozotocindiabetic ketoacidotic rats. Am J Physiol 244 (Endocrinol Metab 7): E151-E158

4. Glanville NT, Anderson GH (1982) Altered methionine metabolism in streptozotocin diabetic rats. Can Fed Biol Sco 25: 316 (Abstract)

5. Musten B, Peace D, Anderson GH (1974) Food intake regulation in the weanling rat: self-selection of protein and energy. J Nutr 104: $563-572$

6. Fernstrom MH, Fernstrom JD (1981) Rapid measurement of free amino acids in serum and CSF using high performance liquid chromatography. Life Sci 29: 2119-2130

7. Herbert V, Low KS, Gottlieb CW, Bleicher SJ (1965) Coated charcoal immunoassay of insulin. J Clin Endocrinol Metab 25: 1375-1384

8. Gaull GE, Rassin DK, Sturman JA (1969) Enzymatic and meta- bolic studies of homocystinemia: effects of pyridoxine. Neuropadiatra 1: $199-226$

9. Gaitonde MK (1967) A spectrophotometric method for the direct determination of cysteine in the presence of other naturally occurring amino acids. Biochem J 104: 627-633

10. Lowry OH, Rosebrough NJ, Fan AL, Randell RJ (1951) Protein measurement with the folin phenol reagent. J Biol Chem 193: 265-275

11. Steel RGD, Torrie JH (1960) Principles and procedures of statistics. McGraw Hill, Toronto

12. Laguens RP, Candela S, Hernandez RI, Galiardino JJ (1980) Streptozotocin-induced liver damage in mice. Horm Metab Res 12: 197-201

13. Feldman S, Scharp D, Hirshberg G, Dodi G, Ballinger W, Lacy P (1977) Streptozotocin-induced liver tumors. Transplantation 24: 152-154

14. Finkelstein JD (1962) Methionine metabolism in mammals: effects of age, diet and hormones on three enzymes of the pathway in rat tissue. Arch Biochem Biophys 122: 583-590

15. Steele RD, Benevenga NJ (1978) Identification of 3-methylthiopropionic acid as an intermediate in mammalian methionine metabolism in vitro. J Biol Chem 253: 7844-7850

16. De Castro JM, Balagura S (1975) Meal patterning in the streptozotocin diabetic rat. Physiol Behav 15:259-263

17. Sauberlich HE (1961) Studies on the toxicity and antagonism of amino acids for weanling rats. J Nutr 75: 61-71

18. Benevenga NJ, Harper AE (1968) Alleviation of methionine and homocystine toxicity in the rat. J Nutr 93: 44-52

19. Klavins JV, Kinney TD, Kaufman N (1963) Histopathologic changes in methionine excess. Arch Pathol 75: 661-673

20. Kaufman N, Klavins JV, Kinney TD (1960) Pancreatic damage induced by excess methionine. Arch Pathol 70: 331-337

21. Stekol JA, Szaran J (1962) Pathological effects of excessive methionine in the diet of growing rats. J Nutr 77: 81-90

Received: 23 September 1983

and in revised form: 23 July 1984

Dr. G.H.Anderson

Department of Nutritional Sciences

Faculty of Medicine

Fitzgerald Building

University of Toronto

Toronto, Ontario, Canada

M5S $1 \mathrm{~A} 8$ 